\title{
Why are Crops Prone to Show Symptoms of Calcium Deficiency in Abnormal Weather
}

\section{Mingzao Liang* Shuxiang Zhang}

Institute of Agricultural Resources and Agricultural Regional Planning, Chinese Academy of Agricultural Sciences, Beijing, 100081, China

\begin{tabular}{|c|c|}
\hline ARTICLE INFO & ABSTRACT \\
\hline Article history & Calcium is an essential element for crops and requires a large amount. \\
\hline Received: 19 March 2020 & The calcium absorbed by plants plays a variety of roles in their bodies, \\
\hline Revised: 26 March 2020 & $\begin{array}{l}\text { such as promoting the development of cell walls, reducing the extrava- } \\
\text { sation of nutrients in the body inhibiting the infection of pathogens, and }\end{array}$ \\
\hline Accepted: 24 April 2020 & improving the resistance of plants. Disease, eliminate the harm of exces- \\
\hline Published Online: 30 April 2020 & sive organic acids in the body, and promote various metabolic processes \\
\hline $\begin{array}{l}\text { Keywords: } \\
\text { Crops prone }\end{array}$ & $\begin{array}{l}\text { body will be blocked, and various symptoms of calcium deficiency will } \\
\text { occur. The paper introduces the symptoms of crop calcium deficiency and } \\
\text { preventive measures. }\end{array}$ \\
\hline
\end{tabular}

\section{Why are Crops Deficient in Calcium under Abnormal Weather in Recent Years?}

$\mathrm{I}$ $\mathrm{n}$ recent years, there are more abnormal weather. Experts estimate that from now on to the end of this century, abnormal weather caused by global climate change will occur frequently. For agriculture, in the next few decades, favorable weather will become scarce, and abnormal weather will become normal. How to deal with the increasingly normalized abnormal weather will become a topic of common concern to the agricultural circles. It has been found that in recent years, under the abnormal weather such as low temperature and cold injury in spring and high temperature and rainy in summer, many crops show symptoms of calcium deficiency, which is common in field crops, fruit trees and vegetables.

In 2018, bitter pox caused by calcium deficiency appeared on the surface of Apple bags just after picking (Figure 1).

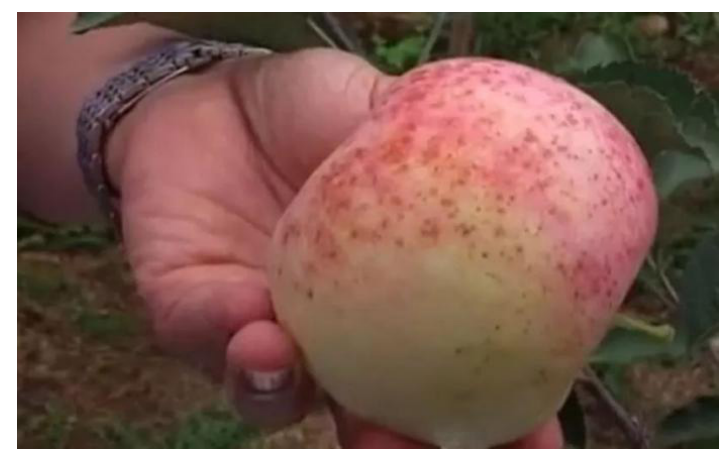

Figure 1. Bitter pox caused by calcium deficiency appeared on the surface of Apple bags

In May 2020, the core leaves of Cucumber in Greenhouse in Shandong Province showed cup-shaped calcium deficiency (Figure 2).

*Corresponding Author:

Mingzao Liang,

Institute of Agricultural Resources and Agricultural Regional Planning, Chinese Academy of Agricultural Sciences, Beijing, 100081, China;

E-mail:lmz@nassg.org 


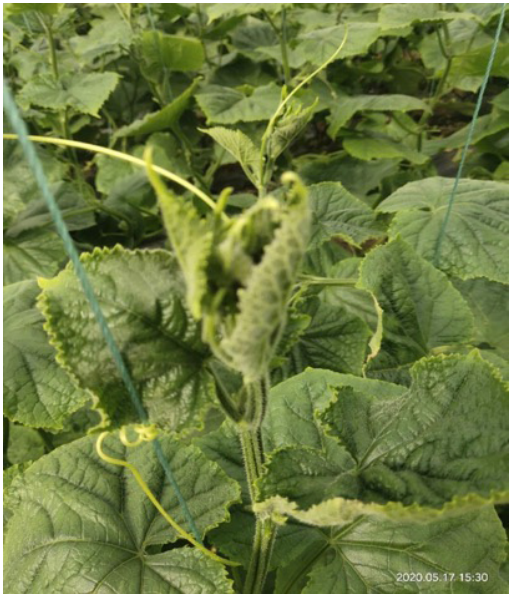

Figure 2. Core leaves of Cucumber in Greenhouse in Shandong Province showed cup-shaped calcium deficiency

In 2020, during the period from booting to maturity, the core leaf of Winter Wheat in Henan Province will be generally shrunken and curly (Figure 3 ).

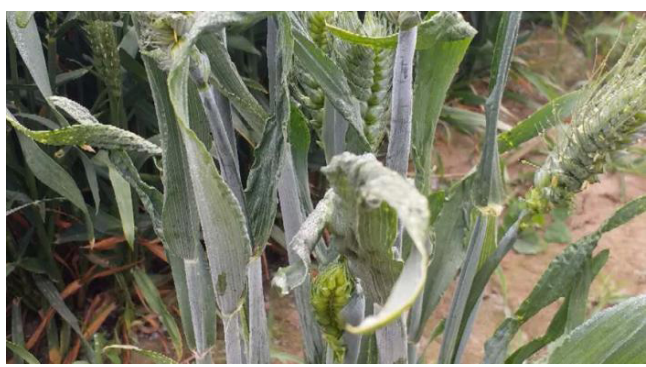

Figure 3. Core leaf of Winter Wheat in Henan Province will be generally shrunken and curly

\subsection{Causes and Manifestations of Calcium Defi- ciency in Crops}

Calcium is an essential medium nutrient element for plants. At present, calcium deficiency is very common in crops in China. The reasons of crop calcium deficiency are as follows: 1) the soil is short of calcium. Calcium deficiency is common in sandy soil and southern red soil (acid soil). 2)Since calcium is transported in plants along with transpiration, the transpiration intensity of fruit trees and vegetables, fruits and vegetables and leafy vegetables is much lower than that of leaves, and the competition for calcium is much smaller than that of leaves. Sometimes it even happens that the calcium in the fruit flows back into the leaves, and the calcium cannot move and be used again in the plant. Calcium deficiency causes the apical buds and the root tips not to develop, showing symptoms of "broken neck". The young leaves are chlorosis, deformed, and hook-shaped. When calcium deficiency is severe, the growth points are necrotic and the leaf tips and growth points are pectin-like. Roots often turn black and rot when calcium deficiency occurs. Generally, fruits and stor- age organs have very poor calcium supply capacity. Fruits and vegetables are often judged as calcium deficiency due to deformation of storage tissues. The young leaves of cereal crops are curled and dry, and the inter-leaf and leaf margins of the functional leaves are withered. The plant declines before it gets old. Less sturdiness, more scabs. In production, a large amount of high-concentration quick-acting phosphorus and potassium fertilizers are used so that form an antagonism to calcium ${ }^{[2]}$ (Figure4-6).

The young leaves of wheat were curled and withered due to calcium deficiency, and the functional leaves were wilted. The plants are old before they are old. It has less fruit and more grains. The most obvious characteristic of calcium deficiency in wheat is that the root tips secrete spherical transparent mucus (Figure 4).

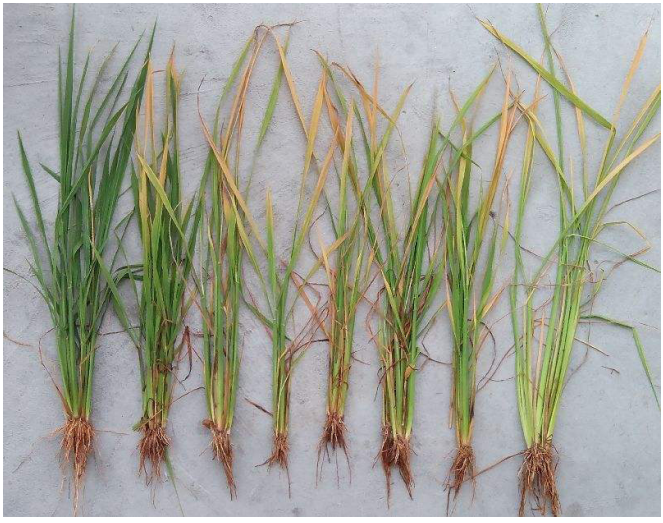

Figure 4. Calcium deficiency in wheat

Rice leaves with calcium deficiency have white markings on the leaf margins, often jagged and irregular lateral cracking, and the top leaf rolls are bent downward in a "bow" shape. Adjacent leaves are often sticky and cannot be extended normally (Figure 5).

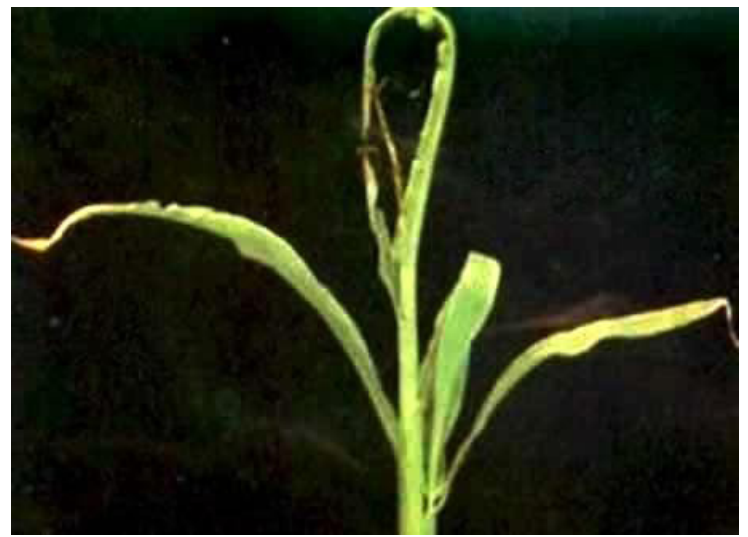

Figure 5. Calcium deficiency in rice

The young organs of corn are first affected when calcium is insufficient, the growth point is damaged, and the heart leaves wither and die; soon after the new roots grow out, they will die and collapse (Figure 6). 


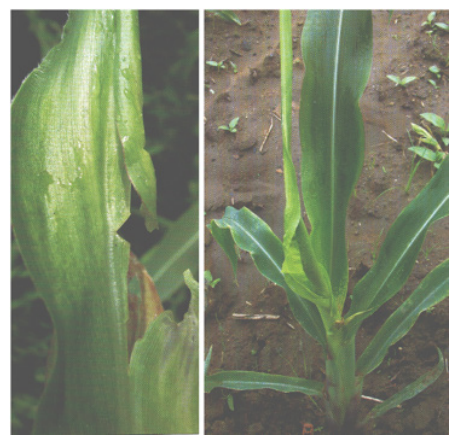

Figure 6. Calcium deficiency in corn

A light green band appeared on the leaf margin of the young leaflets of the early terminal buds, and later necrosis caused the leaflets to shrink or twist. In severe cases, the terminal buds or axillary buds died. The roots are prone to necrosis, the tubers are small, there are malformed clusters of small tubers, and there are necrotic spots in the tuber of the tuber (Figure 7).

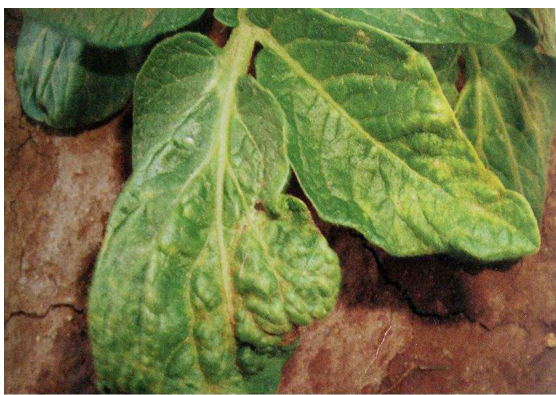

Figure 7. Calcium deficiency in potato

The symptoms of calcium deficiency in cauliflower are as follows: the plant is short, the meristem of stem and root tip is damaged, the growth and development of the top leaf is blocked and deformed, and light brown spots occur; the vein of leaf turns yellow and begins to wither from the upper leaf; the obvious period of symptoms is that after the cauliflower begins to nodulate, the leaf tip and leaf edge of the bulblet turn over, the leaf edge gradually withers and turns yellow, and the leaf edge is withered and necrotic (Figure 8).

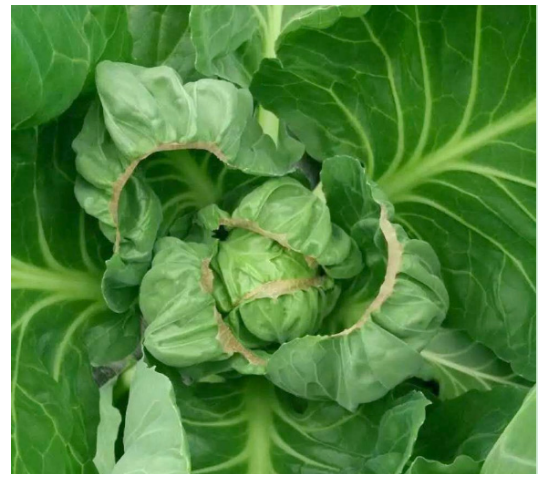

Figure 8. Calcium deficiency in cauliflower
Calcium in plants is easy to form insoluble calcium salt precipitation and fixation, so it cannot be moved and reused. The growth point of cotton with calcium deficiency was restrained, and it was in the shape of crooked hook. When it was serious, the upper leaves and petioles of some old leaves drooped and festered (Figure 9).

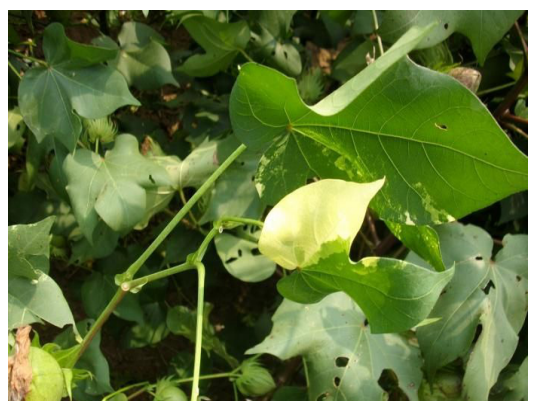

Figure 9. Calcium deficiency in cotton

After calcium deficiency, the whole plant is relatively short, with small branches and drooping leaves. The yellow edge of the top leaf will appear at the beginning, and in serious cases, it will die completely. Gradually, the middle leaves appeared rhubarb and necrotic. During fruit growth, calcium deficiency will crack fruit and abnormal coloring. There are brown fruit, green back fruit. These symptoms caused by calcium deficiency are also called umbilical rot (Figure 10).

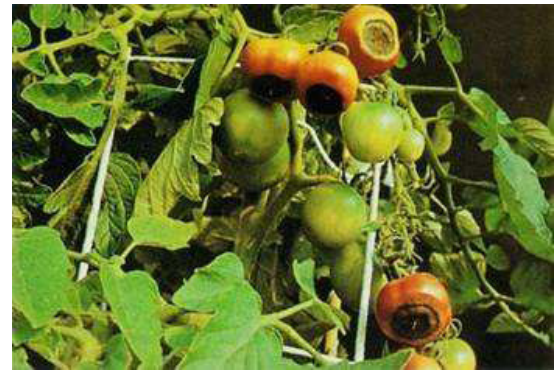

Figure 10. Calcium deficiency in tomatoes

Peanut is short of calcium, the plant grows slowly, the root is thin, the seedling is weak, the edge and surface of the old leaves will appear irregular white spots, the petiole becomes weak, the new leaf is small, the single kernel fruit, the withered fruit and the empty fruit increase obviously, which affects the peanut yield (Figure 11).

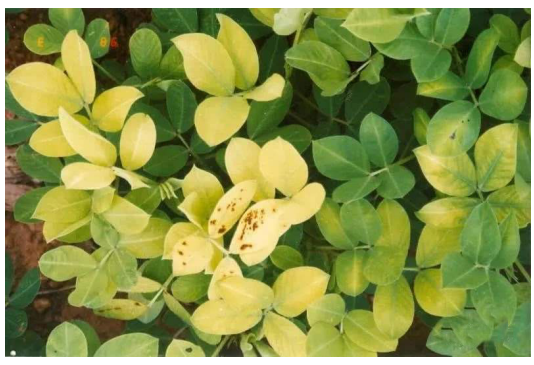

Figure 11. Calcium deficiency in peanut 
Cauliflower calcium deficiency, young leaf margin dry inside roll(Figure 12).

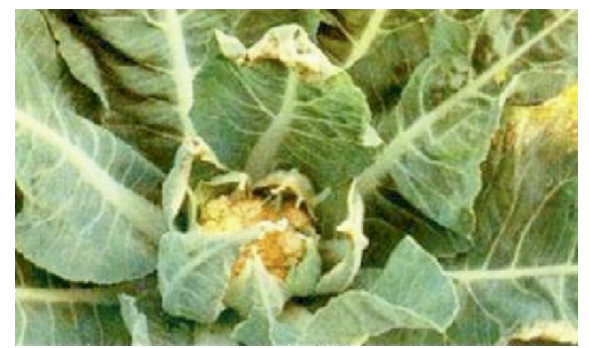

Figure 12. Calcium deficiency in cauliflower

The apex of the inflorescence is curved and the growing point is damaged until necrosis, show "cut neck" symptom. Apical and apical growth stagnated (Figure 13).

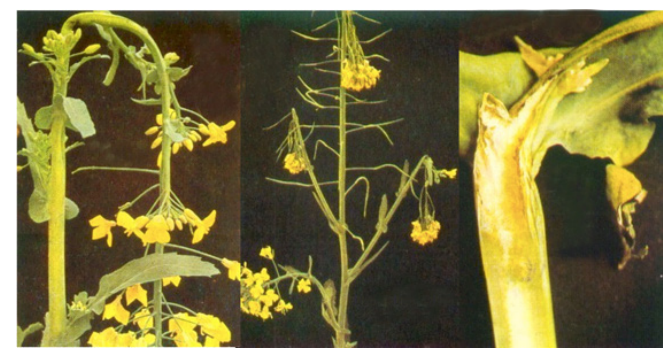

Figure 13. Calcium deficiency in rapeseed

Calcium deficiency in citrus, new leaf tip scorched, leaf curl (Figure 14).

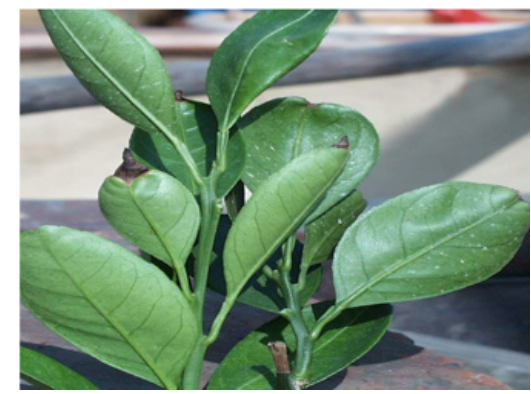

Figure 14. Calcium deficiency in citrus

Calcium deficiency of soybean new leaves do not stretch, old leaves gray - white spots. Leaf veins brown. The handle is soft and pendent. The roots are dark brown, fragile, and thick, with petiole and leaf blade. Dark brown in place, when serious, the stalk apex curl is hook - shaped dead (Figure 15).
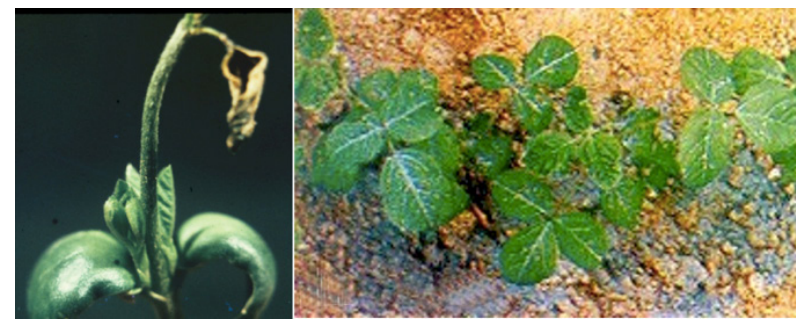

Figure 15. Calcium deficiency in soybean
Calcium content in the skin and pulp tissues of peach calcium-deficient fruit is softened in the suture line low. Lack of calcium leaves of peach leaf spot withered, calcium fruit easy to appear soft rot (Figure 16).

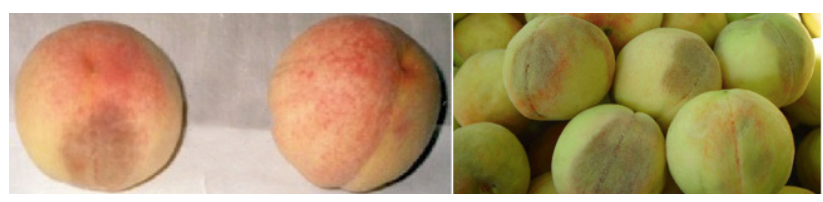

Figure 16. Calcium deficiency in peach

\subsection{Analysis of the Causes of Calcium Deficiency in Crops}

Most producers still don't know that calcium is an element needed by both soil and crops. The demand for calcium in crops is 2.5 times that of phosphorus. Calcium is a bridging substance between soil organic colloids and inorganic colloids, which together form aggregates with other divalent cations. They don't know that the absorption of calcium by crops is very difficult. It needs to be absorbed by the root tip and pulled by transpiration. Under abnormal weather, crop transpiration is affected, and the absorption of calcium by crops is prone to obstacles. Not to mention that calcium is the total regulator of plant cell metabolism. Calcium can stabilize cell membranes against free radical attacks caused by abiotic stress. Calcium ultimately affects the formation of grains.

After more than 40 years of continuous chemical agriculture, the soil calcium reserves and soil calcium used in production can no longer meet the needs of crops and soil. However, no matter in the material supply link or in the production link, calcium supplementation is not on the agenda at present. It is difficult for farmers to buy materials like calcium-magnesium phosphate fertilizers in the agricultural material market. Some high-end liquid calcium on the market is relatively expensive. Buying it can only help farmers for emergency and cannot solve the problem fundamentally. On the contrary, many farmers are inseparable from high-concentration quick-acting phosphorus and potassium fertilizers. Excessive amounts of phosphorus and potassium are antagonistic to calcium and magnesium, which further leaving crops in a hidden hunger for calcium. Therefore, in the event of abnormal weather, crops need calcium to adjust and cope with adversity, and it will not be able to raise so much calcium for a while, and calcium deficiency will appear.

\subsection{Crop Calcium Deficiency Affects Human Health}

In 2015, a survey report issued by the Chinese Center for 
Disease Control and Prevention Nutrition. The surveys were conducted in 2000, 2004, 2009 and 2011, involving Liaoning, Heilongjiang, Shandong, Henan, Hubei, Hunan, Jiangsu, Guizhou, Guangxi. There are more than 14,000 women of childbearing age between 25 and 45 years old in provinces and cities. The daily dietary intake compliance rate of adult women in our country, and the average calcium compliance rate is only about $3 \%$. This big data statistics result is shocking. It shows that there is indeed a problem with chemical agriculture in our country, because $95 \%$ of human food comes from the soil. Soil calcium deficiency leads to calcium deficiency in crops, and calcium deficiency in crops causes food chain effects which affect calcium deficiency in the population. The World Health Organization (WHO) announced that Of the 135 basic diseases, 106 are related to calcium deficiency. The basic diseases include osteoporosis, bone hyperplasia, hypertension, arteriosclerosis, cardiovascular and cerebrovascular diseases, Alzheimer's disease, diabetes, various stone diseases, and various Allergic diseases, liver disease, nephrotic syndrome, sexual dysfunction, premenstrual syndrome and some cancers, etc.

In short, calcium deficiency affects crop growth and yield, and the problem of calcium deficiency in agricultural products affects human health. This problem should arouse the attention of the whole society.

\section{Calcium is The Total Regulator of Plant Cell Metabolism}

Calcium has a strong function in plants. It regulates the stability of cell walls, maintains membrane structural integrity and permeability, and promotes enzyme activation. As a second messenger, it is responsible for the response and transmission of adversity signals, so it is called the Total adjuster of plant cell metabolism. .

\subsection{The Physiological Functions of Calcium}

Calcium in plants mainly constitutes calcium pectinate, calmodulin, and seeds containing calcium and magnesium phytate, etc. There are a large amount of organic calcium in the vacuole, mainly calcium oxalate, calcium citrate, and calcium malate. The $\mathrm{pH}$ can be adjusted to stabilize the cell environment. Calcium is the pectin structural component of the cell wall and maintains the structure and function of the cell wall. Calcium plays a key role in plant erection and stem stiffness. Its role on cells and cell walls is to regulate the transport of carbohydrates. The amount of calcium pectinate in the cell wall is related to the sensitivity of fungal infection of tissues and the ripening of fruits. Calcium can reduce the risk of disease infection during storage. Calcium can enhance the disease resistance of plants. When calcium is lacking, the adhesion between calcium and pectin in the middle rubber layer is affected, and plant tissues are vulnerable to pathogens. Calcium increases the storage and transportation resistance of agricultural products and makes them not perishable. Calcium promotes the absorption of nitrate nitrogen and reduces the accumulation of nitrate in plants. Calcium can improve the salt tolerance of plants. Nitrogen-fixing bacteria in plants also need a lot of calcium.

\subsection{The Effect of Calcium on Cell Membranes}

Calcium is the link between substances in the cell membrane, and it is a substance necessary for cell elongation. Calcium can increase the activity of superoxide dismutase (SOD), reduce the content of membrane lipid malondialdehyde, and protect the integrity of the cell membrane structure. The damaged membrane system will inevitably lead to the reduction of cell energy conversion efficiency, so protecting the cell membrane system is protecting crops. Low temperature causes a large number of free radicals to be produced in plants, causing damage to the membrane system. Calcium can slow down the rate of decrease of superoxide dismutase (SOD), peroxidase (POD) and catalase (CAT) in plants. These three enzymes are important protective enzymes in plants, which are used to remove free radicals. Calcium can effectively improve the cold resistance of plants. Calcium can also improve the drought resistance and water retention capacity of plants by regulating the activity of certain enzymes.

\subsection{Calcium Occupies a Central Position in Signal Transduction}

Calcium occupies a central position in cell signal transduction. The stress of adversity causes a sharp increase in calcium ions in the cytoplasm. Calcium comes from the cell wall and intracellular calcium stores, namely the vacuole and the endoplasmic reticulum. Calcium is the second messenger of various adversity reactions. When the adversity signal is sent by ethylene, calcium ions $(\mathrm{Ca} 2+)$ are released from some organelles, which in turn activates a specific chemical reaction, calcium ion $(\mathrm{Ca} 2+)$ channels on the plasma membrane When it is turned on, extracellular calcium ions $(\mathrm{Ca} 2+)$ enter the cell, and $\mathrm{Ca} 2+$ binds to a special calmodulin. In a series of cascade reactions, the calmodulin complex activates the third messenger abscisic acid. Passed to the second messenger calcium ions activate transcription factors to express stress resistance genes. The calcium signal is sensed and transduced by the calcium binding protein $(\mathrm{CaM})$ downstream of it, which 
then causes a series of biochemical reactions in the cell to adapt to or resist various adversity stresses.

\subsection{It is Not Easy For Crops to Absorb Calcium}

The calcium requirement of crops is 2.5 times that of phosphorus, but it is not easy for plants to absorb calcium. It is necessary to rely on transpiration to pull plants to absorb calcium in the form of divalent calcium ions. Although the content of calcium in the soil is sometimes 10 times greater than that of potassium, the amount of calcium absorbed by plants is much less than that of potassium, because calcium can only be absorbed by young root tips that have not been plugged in the endothelial cell wall of plant roots, so the ability of plants absorbing calcium is limited. The speed at which calcium moves upward is largely affected by the intensity of transpiration. Old leaves with high transpiration rate transport more calcium. Although the transpiration rate of the newly-born shoots and fruit parts of plants is low, the ability to synthesize auxin (indole acetic acid) can stimulate the proton pump to increase new cation exchange points, promote the movement of calcium to the fruit, and accumulate calcium in the fruit. It is a good remedy to spray liquid calcium on the fruit surface in time during the young crop period.

\section{Supplementing Calcium Should Consider the Dual Needs of Crops and Soil}

The calcium content in the earth's crust is about 3.64\%. The source of calcium in the soil is anorthite, pyroxene and amphibole, which are common in the soil. There are also calcite, dolomite, gypsum, biotite, epidote, and apatite. Calcium is also contained in minerals such as stone and albite. The calcium content of soil in our country is very different. Wet areas have low calcium content, sandy soil low calcium content, and calcareous soil high calcium content. The leaching loss of calcium is more than that of sodium. Calcium is the most abundant ion in leaking water, spring water, river water, and lake water. In acidic soils in hot and humid areas, calcium bicarbonate dissolved in water is easily leached out with water flow, so soils in hot and humid areas are prone to calcium deficiency and the soil is acidic. Alkaline soils in arid regions contain relatively more calcium.

\subsection{Lack of Calcium in the Soil Is the Cause of Soil Compaction}

The exchangeable calcium loss of the soil solution is lost with drainage, carried out of the farmland by crops, adsorbed by the clay particles in the soil to form a bridging material forming the soil aggregate structure, and antago- nizes potassium ions to re-precipitate (Figure 17).

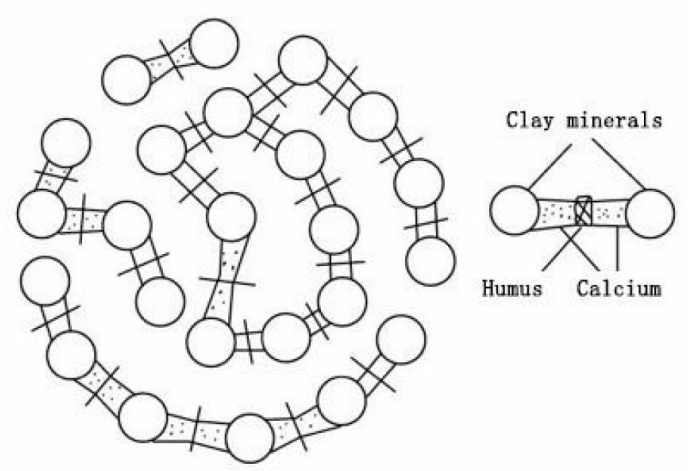

Figure 17. Calcium is a divalent cation and a bridging substance in the soil structure

The formation of soil aggregate structure is a sign of soil health, and the formation of soil aggregate structure is inseparable from the bridging effect of divalent cations. The clay minerals in the soil-forming parent material are also called inorganic colloids with negative charges, and the humus in the soil is also called organic colloids with both positive and negative charges. The soil forms a combination of organic colloid and inorganic colloid, which requires divalent mineral cations to bridge. Studies have shown that soils with aggregate structure have the following three combinations. That is, G1 clay minerals-calcium and magnesium divalent cations-humus, G2 clay minerals-divalent iron manganese cations-humus, and G3 clay minerals-humus (Figure 18).

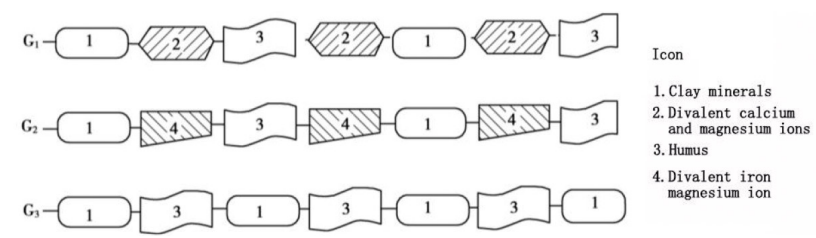

Figure 18. Combination model diagram of clay minerals-divalent cations-humus

Years of planting and harvested crops carry a large amount of minerals from the farmland, destroying the original accumulation of soil minerals. The reason why chemical agriculture hardens the soil is because the divalent cations in the soil that act as a bridge between organic and inorganic colloids are replaced by the more active monovalent cations in chemical fertilizers (Figure 19). When any one of potassium ions, ammonium ions and sodium ions in the soil accounts for $12-15 \%$ of the amount of soil base substitution, the divalent cations in the soil structure are replaced, and the soil structure is destroyed ${ }^{[1]}$. In soils that have been chemically planted for many years, and soils with poor aggregate structure and low organic matter, the effectiveness of trace elements will be greatly reduced, and more attention should be paid to the use of trace mineral 
elements. Although crops have low requirements for trace elements, they cannot be ignored for a long time.

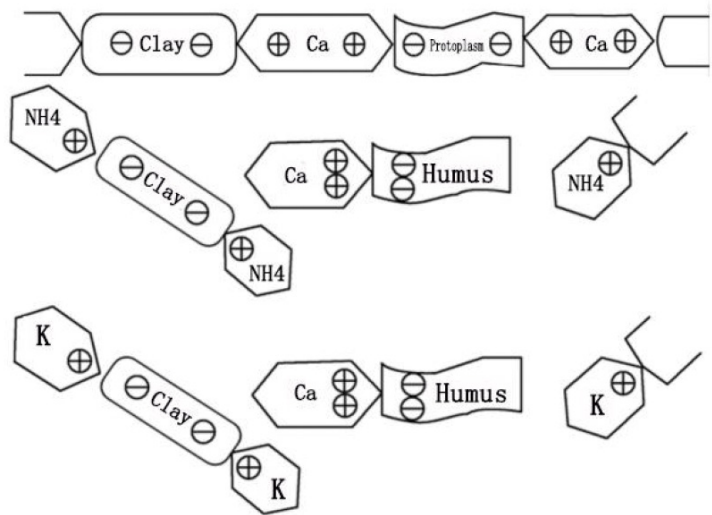

Figure 19. Schematic diagram of soil structure destruction caused by excess monovalent cations in the soil

\subsection{Calcium Supplementation Should Consider the Ratio of Calcium, Magnesium and Potassium}

In fertilization, it is necessary to consider the needs of crops and soil for calcium and magnesium. When adding minerals to the soil, not only rely on the amount of crop removed, but also consider the availability of soil minerals. Generally, the critical value of soil available potassium $(\mathrm{K})$ is $80 \mathrm{mg} / \mathrm{Kg}$, the critical value of effective magnesium $(\mathrm{Mg})$ is $120 \mathrm{mg} / \mathrm{kg}$, the critical value of available calcium $(\mathrm{Ca})$ is $400 \mathrm{mg} / \mathrm{kg}$, and the critical value of soil available phosphorus (P) is $12 \mathrm{mg} / \mathrm{kg}$. The ratio of available magnesium to available potassium in the soil is an important indicator of soil properties. Studies have shown that the $\mathrm{Mg} / \mathrm{K}$ ratio in the soil is more appropriate at 3.7$15: 1$, and the effective $\mathrm{Ca} / \mathrm{Mg}$ ratio in the soil is around 2.4-7. It can be seen from the above data that the value of available calcium and available magnesium required in the soil should be far greater than the value of available potassium. It is more reasonable to supplement the soil with a calcium-magnesium-potassium ratio of approximately 5:2:1. The chelated form of trace elements is easier to be absorbed by crops. Elemental micro-fertilizers are best used together with organic materials such as straws in the base fertilizer. When the organic materials gradually evolve into humus after fermentation, they have a chelating effect on the trace elements. The combined trace elements have better physiological activity, are not easy to be fixed by the soil, and the utilization rate of crops is high.

\section{How to Supplement Calcium in Agriculture Is an Important Topic}

Therefore, how to supplement calcium in agricultural production is still an important topic. Calcium magnesium phosphate fertilizer has national standards. Calcium magnesium phosphate fertilizer can supplement the needs of crops for calcium, magnesium, phosphorus and trace elements. From the perspective of crop demand, calcium magnesium phosphate fertilizer is a fertilizer with a reasonable combination of medium and trace elements. It should become the majority of agricultural producers. The first choice when reapplying base fertilizer. There are not many specialized calcium fertilizers in the market. Lime can be used as calcium fertilizer for acidic soils, and gypsum can be used as calcium fertilizer for alkaline soils. The principle of gypsum for improving saline-alkaline soil is that calcium replaces the sodium on the soil clay and combines with sulfur to form Sodium sulfate is discharged with water to make soil flocculate and water permeability better. There are also superphosphate and double superphosphate in calcium fertilizer. Calcium nitrate fertilizer is a kind of fertilizer that contains both nitrogen and calcium. It has good solubility and can be sprayed on the leaves. The disadvantage is that it has high hygroscopicity. The new chelated calcium or marine active calcium fertilizer can also be used as a calcium source supplement.

In short, the above-mentioned calcium fertilizers are all urgently needed materials for crops. In order to make the crops grow well and produce high yields, please pay attention to calcium supplementation. It is recommended to reapply calcium fertilizers in the base fertilizer. It is a good remedy to spray liquid calcium on the fruit surface in time during the young crop period.

\section{References}

[1] Zhou Wei, Li Shutian, Lin Bao. Review and prospect of research on crop sulphur and calcium nutrition [J]. Chinese Agricultural Sciences, 2007 (01): 250-255.

[2] [America] S. L. Tisdale, author. Translated by Jin Jiyun, Liu Rongle, etc. Soil Fertility and Fertilizer [M] China Agricultural Science and Technology Press, 1998.

[3] Du Wenjuan, Wang Huijun, Chen Shaojie. Changes in dietary nutrient intake of adult women in 9 provinces (regions) of China from 2000 to 2011[J]. Chinese Journal of Epidemiology, 2015(36):715-719.

[4] Zhao Fangjie, Xie Wanying, Wang Peng. Soil and human health [J]. Acta Pedologica Sinica, 2020(01):110.

[5] Liang Mingzao, Lu Sen, Zhang Shuxiang. High-yield and High-quality Cultivation System of Ecological Agriculture in China [M]. Beijing: China Agricultural University Press, 2017. 